\title{
INVESTIGATION OF WEAR RESISTANCE OF PROTECTIVE COATINGS UNDER CONDITIONS OF HYDROABRASIVE WEAR
}

\author{
B.V. STEFANIV \\ E.O. Paton Electric Welding Institute, NASU \\ 11 Kazimir Malevich Str., 03680, Kiev, Ukraine. E-mail: office@paton.kiev.ua
}

\begin{abstract}
Increase of service life of the drill bits with protective coatings, operating under conditions of abrasive, erosion and corrosion wear, is the most relevant problem in Ukraine. Aim of present work is to study wear resistance of the protective coatings under conditions of hydroabrasive wear. The investigation of wear resistance was made on the protective coatings, containing tungsten carbides, TeroCote 7888T, Diamax M and relite LZ-11-7, being arc deposited on steel 45, under conditions of abrasive wear. It is determined that wear resistance of relite LZ-11-7 and Diamax M composite alloys, consisting of Fe-based reinforcing particles (fused spherical and crushed tungsten carbide), has selective character and insignificant dependence on properties and hardness of a matrix. Application of Ni-based composite alloy TeroCote 7888T (split tungsten carbide) provides for efficient protection under conditions of hydroabrasive wear. At room temperature the wear resistance of the protective TeroCote $7888 \mathrm{~T}$ coating 1.5 and 2 times exceeds the wear resistance of relite LZ-11-7 and Diamax M, respectively. This alloy allows increasing service life of the protective coatings of reconditioned defect areas of drill bits' bodies, which operate under heavy conditions of corrosion-abrasive wear. 10 Ref., 3 Tables, 5 Figures.
\end{abstract}

Keywords : surfacing, surfacing consumables, tungsten carbides, structure, strength, wear resistance, composite alloys, hardness, relite

In recent decades, the steel drill bits with protective coatings of work tools have acquired wide application in drilling of gas and oil wells. Carried analysis of the waste drill bits having protective coatings showed that drilling mostly provokes wear of blades, seats and less often fluid-discharge ports of the drill bits' bodies [1-4]. The specific attention was paid on wear of the blade seats, since the blades take the major load in drilling. Mechanic interaction with mine rock provides for breaking of the blades as well as the seats. The wear-resistant coatings preserve the seats of cutting blades and the assemblies of fluid-discharge ports of drill bits' bodies from hydroabrasive and corrosion wear.

Increase of service life of the drill tool operating under conditions of hydroabrasive wear and impact loading is a relevant problem in Ukraine. Currently, there are only methods for reconstruction of worn blades of the drill bits. Reconstruction of the protective coatings of the seats of work tools requires reconstruction of geometry of the base metal opening, i.e. deposition of intermediate layer of base metal and after this a layer of protective hard-alloy coating using different methods. The leading foreign companies have been using the wear-resistant coatings of different functional designation in their products for a long time [5-9].

(C) B.V. STEFANIV, 2016
The main task of this work is an investigation of wear resistance of the protective coatings under conditions of hydroabrasive wear.

Surfacing composite alloys consisting of reinforcing WC particles and matrix differ by high wear resistance under conditions of abrasive, erosion and corrosion wear. A typical peculiarity of the wear-out process of such alloys is a step-by-step wear of the separate components of the composition. At that, such a called shadowing effect, when the prominent more wear-resistant reinforcing particles bear the major load of the destructive forces, thus preserving alloy matrix from wear, can be observed.

The protective coating is a surface layer of the drill bit work tool, which is intentionally developed by environment effect on drill material surface and characterized by final thickness as well as chemical composition and structure-phase state different from the similar characteristics of base metal. The existing methods of coating deposition over the base metal can be classified as mechanical, physical, chemical and electro-physical on production method; galvanic, vacuum and deposits on methods of technological process; wear-, corrosion-, heat-resistant and others on their functional designation.

The results of investigation of technology of drill bits repair [2-4] were used for carrying out the works on selection of a method of protective coating deposition on the worn parts of bodies' work tool. The properties 


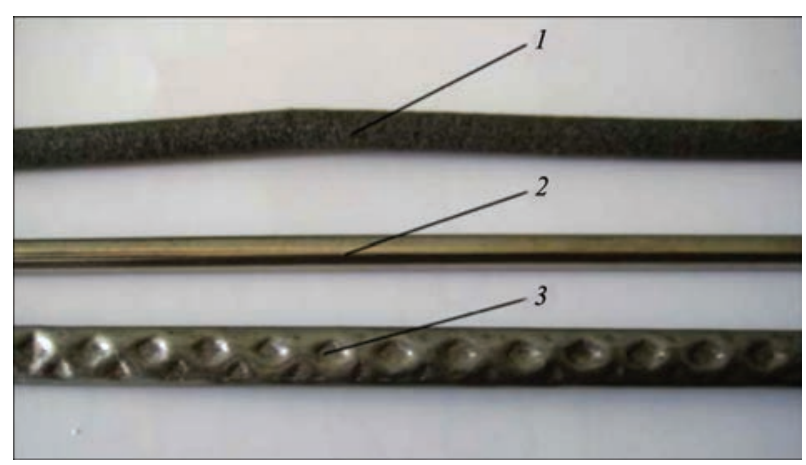

Figure 1. Appearance of surfacing consumables: 1 - TeroCote $7888 \mathrm{~T}$ (Castolin) based on nickel; 2 - Diamax M (Castolin) based on iron; 3 - relite LZ-11-7 (Ukraine) based on iron

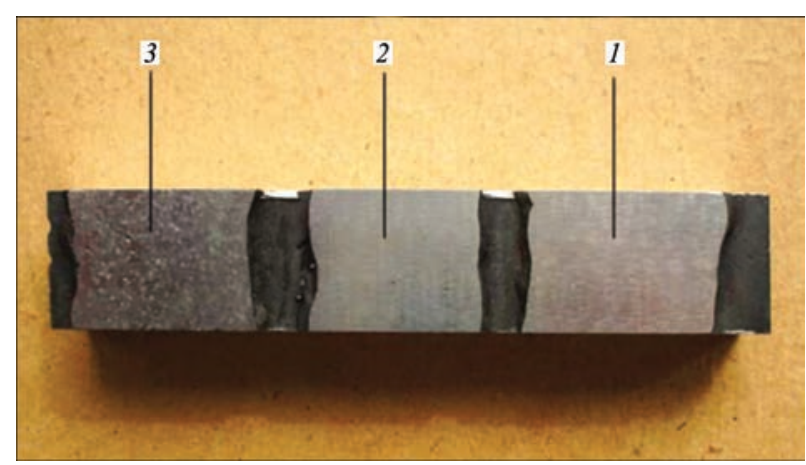

Figure 2. Macrostructure of specimen with protective coatings deposited using surfacing consumables: 1 - TeroCote 7888T; 2 - Diamax M; 3 - relite LZ-11-7
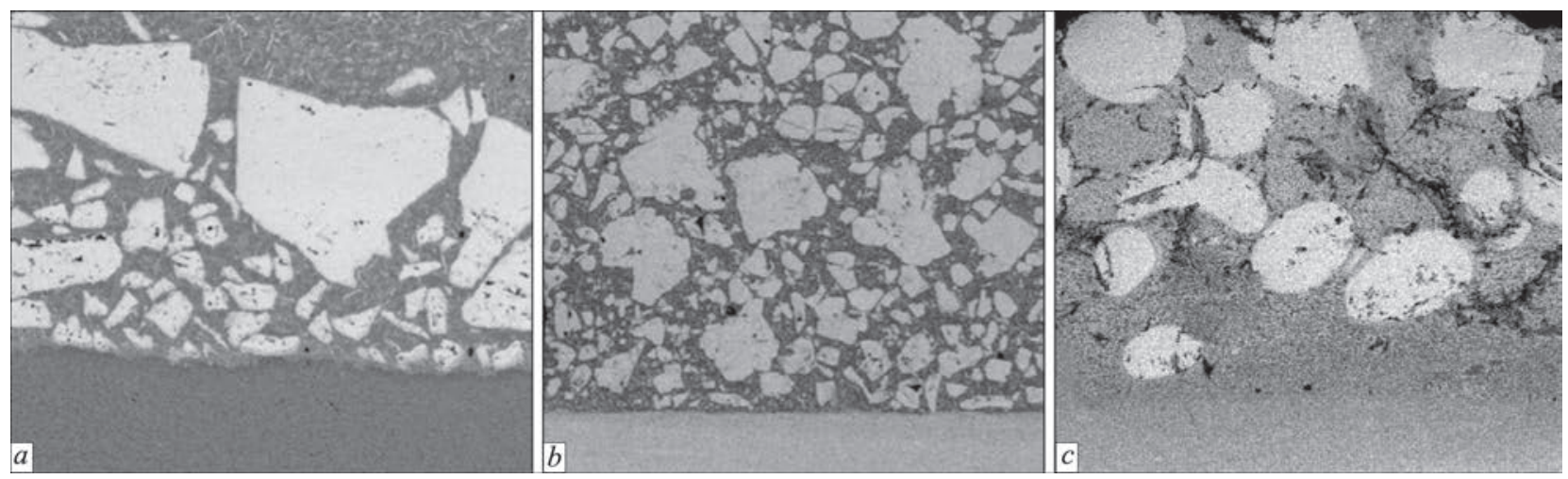

Figure 3. Microstructure (x100) of metal of coatings produced using filler materials: $a$ - TeroCote 7888T; $b-$ Diamax M; $c$ - relite LZ-11-7

of existing wear-resistant materials and reconstruction technology, which could provide all physical-chemical properties of the base metal of steel drill body, were investigated for fulfilment of this task.
Composite materials, containing different-based tungsten carbides (Figure 1), were taken for investigation of wear resistance of the protective coatings under conditions of hydroabrasive wear.

Table 1. Composition and hardness of layers deposited on steel 45

\begin{tabular}{|c|c|c|c|c|c|c|c|c|c|}
\hline \multirow[b]{2}{*}{ Surfacing consumables } & \multirow{2}{*}{$\begin{array}{l}\text { Type of tungsten } \\
\text { carbide granules }\end{array}$} & \multicolumn{7}{|c|}{ Composition, wt.\% } & \multirow{2}{*}{$\begin{array}{c}\text { Hardness } \\
\text { HRC } \\
\text { (average) } \\
\end{array}$} \\
\hline & & $\mathrm{C}$ & $\mathrm{Ni}$ & $\mathrm{Cr}$ & $\mathrm{Fe}$ & $\mathrm{Si}$ & W & $\mathrm{Mn}$ & \\
\hline TeroCote 7888T & Split & 9.31 & 33.49 & 3.62 & 1.15 & - & 50.38 & - & 48.3 \\
\hline Diamax M & Crushed & 13.19 & - & - & 27.60 & - & 58.32 & 0.89 & 57 \\
\hline Relite LZ-11-7 & Spherical & 11.98 & - & 0.14 & 21.23 & - & 65.33 & 1.32 & 58.8 \\
\hline Reference specimen & Steel 45 & $0.42-0.50$ & 0.25 & 0.25 & 97 & $0.17-0.37$ & - & $0.5-0.8$ & 30 \\
\hline
\end{tabular}

Table 2. Composition, hardness and wear of deposited layers $(L=250 \mathrm{~m})$

\begin{tabular}{|c|c|c|c|c|c|c|}
\hline \multirow{2}{*}{ Number of specimen } & \multirow{2}{*}{ Surfacing consumables } & \multirow{2}{*}{$\begin{array}{c}\text { Surfacing } \\
\text { method }\end{array}$} & \multirow{2}{*}{$\begin{array}{c}\text { Matrix } \\
\text { hardness } \\
\text { HRC }\end{array}$} & \multicolumn{3}{|c|}{ Mass of specimens, g } \\
\hline & & & & Before & After & Difference \\
\hline Reference specimen 1 & Steel 45 & - & 30 & 12.82 & 12.51 & 0.31 \\
\hline 1.1 & \multirow{3}{*}{ TeroCote $7888 \mathrm{~T}$} & Arc & 45 & 14.26 & 14.23 & 0.03 \\
\hline 1.2 & & Arc & 50 & 13.95 & 13.91 & 0.04 \\
\hline 1.3 & & Arc & 50 & 14.32 & 14.28 & 0.04 \\
\hline Reference specimen 2 & Steel 45 & - & 30 & 12.90 & 12.59 & 0.31 \\
\hline 2.1 & \multirow{3}{*}{ Diamax M } & Arc & 56 & 14.36 & 14.26 & 0.10 \\
\hline 2.2 & & Arc & 59.5 & 14.28 & 14.20 & 0.08 \\
\hline 2.3 & & Arc & 55.5 & 14.22 & 14.08 & 0.14 \\
\hline Reference specimen 3 & Steel 45 & - & 30 & 12.86 & 12.56 & 0.30 \\
\hline 3.1 & \multirow{3}{*}{ Relite LZ-11-7 } & Arc & 55 & 14.25 & 14.20 & 0.05 \\
\hline 3.2 & & Arc & 60 & 14.23 & 14.16 & 0.07 \\
\hline 3.3 & & Arc & 61.5 & 14.05 & 13.98 & 0.07 \\
\hline
\end{tabular}




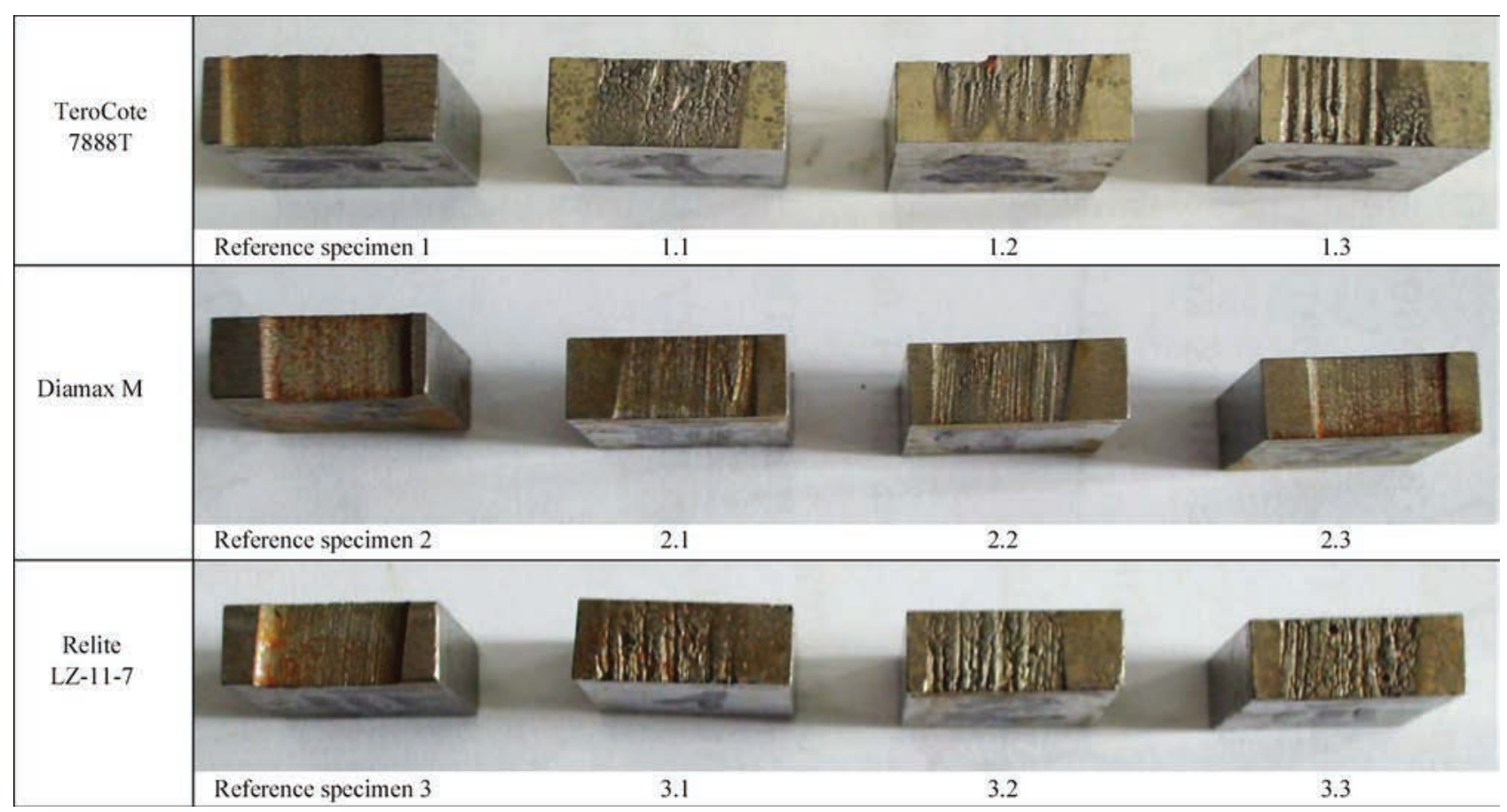

Figure 4. Appearance of specimens, deposited with different composite materials, after hydroabrasive wear testing $(L=250 \mathrm{~m})$

Pilot specimens produced from steel 45 of $20 \mathrm{~mm}$ thickness (Figure 2) were used to investigate the deposits using selected wear-resistant materials. Manual shielded gas (technical argon) TIG welding was taken as a method of surfacing.

Measurements of hardness HRC on the deposit surface were carried out using versatile device TP5006. As a result it was determined that hardness of the deposited layers in surfacing on steel 45 (reference) using filler materials Diamax M and relite LZ-11-7 is on average $15-20 \%$ higher than using TeroCote 7888T (Table 1). Metallographic examinations of the deposited specimens were carried out using optical microscope Neophot-32 (Figure 3). WC particles can be observed in the coatings based on nickel (TeroCote 7888T) and iron (Diamax M and relite LZ-11-7). At that, the reinforcing particles are chaotically located along the deposited bead section. Such an inhomoge- neity of tungsten carbide particle distribution along the deposited bead section is caused by variation of hardness depth and can effect coating resistance to hydroabrasive wear. Works [2-4] show that composite wear-resistant material TeroCore $7888 \mathrm{~T}$ is more perspective. It contains ultra-hard tungsten carbides in a solid matrix of nickel-chromium alloy, which absorbs impact loads and improves resistance to abrasive wear and corrosion, while uniform split profile particles of tungsten carbides make difficult their breakaway from the matrix.

Resistance of the deposited coating to hydroabrasive wear was determined on NK-M machine [10]. Test validity for each composite material was evaluated on three specimens. Quartz glass of $0.05-0.50 \mathrm{~mm}$ was used as an abrasive. The plates of $20 \times 16 \times 6 \mathrm{~mm}$ were applied as specimens. They were produced in the following way. Wear-resistant materials based on nickel

Table 3. Composition, hardness and wear of deposited layer $(L=1250 \mathrm{~m})$

\begin{tabular}{|c|c|c|c|c|c|c|}
\hline \multirow{2}{*}{ Number of specimen } & \multirow{2}{*}{ Surfacing consumables } & \multirow{2}{*}{$\begin{array}{c}\text { Surfacing } \\
\text { method }\end{array}$} & \multirow{2}{*}{$\begin{array}{c}\text { Matrix } \\
\text { hardness } \\
H R C\end{array}$} & \multicolumn{3}{|c|}{ Mass of specimens, g } \\
\hline & & & & Before & After & Difference \\
\hline Reference specimen 1 & Steel 45 & - & 30 & 12.20 & 10.70 & 1.50 \\
\hline 1.1 & \multirow{3}{*}{ TeroCote $7888 \mathrm{~T}$} & Arc & 45 & 12.07 & 11.85 & 0.22 \\
\hline 1.2 & & Arc & 50 & 13.57 & 13.39 & 0.18 \\
\hline 1.3 & & Arc & 50 & 13.95 & 13.70 & 0.25 \\
\hline Reference specimen 2 & Steel 45 & - & 30 & 12.18 & 11.30 & 1.50 \\
\hline 2.1 & \multirow{3}{*}{ Diamax M } & Arc & 56 & 13.93 & 13.53 & 0.40 \\
\hline 2.2 & & Arc & 59.5 & 13.84 & 13.29 & 0.55 \\
\hline 2.3 & & Arc & 55.5 & 13.87 & 13.56 & 0.31 \\
\hline Reference specimen 3 & Steel 45 & - & 30 & 12.15 & 10.66 & 1.49 \\
\hline 3.1 & \multirow{3}{*}{ Relite LZ-11-7 } & Arc & 55 & 13.64 & 13.35 & 0.29 \\
\hline 3.2 & & Arc & 60 & 13.85 & 13.64 & 0.21 \\
\hline 3.3 & & Arc & 61.5 & 13.69 & 13.20 & 0.49 \\
\hline
\end{tabular}


and iron with tungsten carbide were deposited on plate of $22 \times 20 \times 100 \mathrm{~mm}$ size (see Figure 2) by arc surfacing. Thickness of the deposited layers made 5-7 mm. After surfacing the specimens of $21 \times 17 \times 7 \mathrm{~mm}$ were cut out by erosion. Each specimen was polished to bring to necessary size of $20 \times 16 \times 6 \mathrm{~mm}$. Thickness of the deposited layer made $3 \mathrm{~mm}$. Wear of the specimen was evaluated on loss of its weight (Figure 4, Table 2). Weighing was carried out on electronic scales OHAUS with measurement accuracy $0.01 \mathrm{~g}$. At that specific loading on the specimen made $0.5 \mathrm{MPa}$, friction velocity $0.58 \mathrm{~m} / \mathrm{s}$, friction distance $250 \mathrm{~m}$.

Wear resistance of the composite alloys in hydroabrasive wear was evaluated by loss of weight of the deposited layer on friction distance. Firstly, wearing out of the matrix takes place, baring the tungsten carbides, which in turn provokes significant delay of wear of the protective coating. And further, after tungsten carbide wear out the cycle is repeated (Figure 4, Table 2). Nature of wear of the deposited layer for all composite materials approaches to linear dependence (Table 3) at increase of wear distance $(L=1250 \mathrm{~m})$.

Figure 5 shows the average values of wear of the deposited layer of composite alloys in hydroabrasive wear depending on friction distance.

\section{Conclusions}

1. The results of investigations show that resistance to hydroabrasive wear of the protective coating TeroCote $7888 \mathrm{~T}$ with split particles of tungsten carbide is 1.5 and 2 times more than wear resistance of relite LZ-11-7 (spherical granules of tungsten carbide) and Diamax M (crushed particles of tungsten carbide), respectively.

2. Composite material Castolin TeroCote $7888 \mathrm{~T}$ is the most perspective for deposition of the protective coatings on the work tools of drill bits. The protective coatings based on this alloy allow increasing service life of the drill tool at drilling of gas and oil wells.

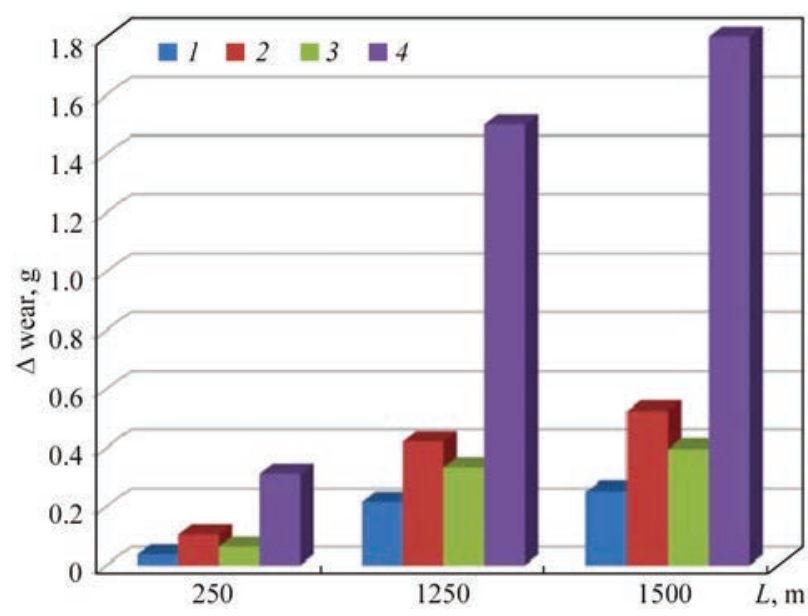

Figure 5. Wear of deposited layer from composite materials and steel 45: 1 - TeroCote 7888T; 2 - Diamax M; 3 - relite LZ$11-7 ; 4$ - steel 45

1. Khorunov, V.F., Stefaniv, B.V., Sabadash, O.M. et al. (2012) Peculiarities of technologies for repair of drill bits with diamond-carbide cutters. In: Problems of service life and safety of structures, constructions and machines: Transact., 488493. Kiev: PWI.

2. Stefaniv, B.V., Khorunov, V.F., Sabadash, O.M. (2014) Features of reconditioning steel drill bit watercourse. The Paton Welding J., 11, 50-54.

3. Stefaniv, B.V., Khorunov, V.F., Sabadash, O.M. et al. (2015) Peculiarities of restoration of working parts of drilling bit matrix bodies. Ibid., 8, 47-50.

4. Stefaniv, B.V., Khorunov, V.F., Sabadash, O.M. et al. (2012) Features of technology for repair of wear working parts of steel and drilling bit matrix bodies. In: Problems of service life and safety of structures, constructions and machines: Transact., 688-696. Kiev: PWI.

5. Information of company Postalloy (USA) for surfacing of protective coatings. http://www.postle.com

6. Information for soldering and surfacing TeroCote ${ }^{\circledR}$. http:// www.castolin.com.ua

7. Surfacing materials BAT-Service. http://www.b-trans.com. ua/qw/id/79

8. Materials for surfacing and spraying. http://www.kennametal.com/stellite

9. Surfacing alloy relite of LZ type.http://www.resource@ aranei.com

10. Yuzvenko, Y.A., Zhudra, A.P., Frumin, E.I. (1973) Abrasive wear of composite alloys. Avtomatich. Svarka, 7, 62-63.

Received 12.04.2016 